\title{
Use of antiviral prophylaxis in influenza outbreaks in long term care facilities
}

\author{
Allison McGeer MD², Daniel S Sitar PhD², Susan E Tamblyn MD³, \\ Faron Kolbe MSc${ }^{4}$, Pamela Orr MD², Fred Y Aoki MD²
}

\begin{abstract}
A McGeer, DS Sitar, SE Tamblyn, F Kolbe, P Orr, FY Aoki. Use of antiviral prophylaxis in influenza outbreaks in long term care facilities. Can J Infect Dis 2000;11(4):187-192.

Influenza is a major cause of illness and death in residents of long term care facilities for the elderly, in part because residents' age and underlying illness increase the risk of serious complications, and in part because institutional living increases the risk of influenza outbreaks. The administration of antiviral medications active against influenza to persons exposed to influenza has been shown to protect them effectively from illness, and mass antiviral prophylaxis of residents is an effective means of terminating influenza A outbreaks in long term care facilities. The only antiviral currently licensed in Canada for influenza prophylaxis is amantadine, a medication active against influenza A but not influenza B. The National Advisory Committee on Immunization recommends that amantadine prophylaxis be offered to residents when influenza A outbreaks occur in long term care facilities. However, there remain a number of unanswered questions about how best to use amantadine for controlling influenza A outbreaks in long term care facilities. In addition, two members of a new class of antivirals called neuraminidase inhibitors have recently been licensed in Canada for the treatment of influenza, and are effective in prophylaxis. Issues in the use of amantadine in the control of outbreaks of influenza $\mathrm{A}$ in long term care facilities for the elderly are reviewed, and the potential uses of neuraminidase inhibitors in this setting are discussed.
\end{abstract}

Key Words: Amantadine; Influenza; Long term care; Neuraminidase inhibitor; Outbreak

\section{L'emploi d'antiviraux à titre prophylactique contre les épidémies de grippe dans les établissements de soins de longue durée}

RÉSUMÉ : La grippe est une importante cause de morbidité et de mortalité chez les résidents des établissements de soins de longue durée, en partie à cause de l'âge des résidents et du fait que la maladie sous-jacente accroît le risque de complications graves et en partie parce que la vie en institution constitue en soi un facteur de risque à l'égard des épidémies de grippe. L'administration d'antiviraux efficaces contre la grippe à des personnes qui y sont exposées s'est révélée être apte à les protéger efficacement de la maladie, et l'administration généralisée d'antiviraux aux résidents est une façon efficace d'enrayer les épidémies de grippe de type A dans les établissements de soins de longue durée. Le seul agent antiviral prophylactique actuellement brevetée au Canada pour enrayer la grippe est l'amantadine, un médicament qui agit contre la grippe de type A, mais non contre la grippe de type B. Le Comité consultatif national sur l'immunisation recommande que le traitement prophylactique à l'amantadine soit offert aux résidents lorsqu'une épidémie de grippe se déclare dans des établissements de soins de longue durée. Un certain nombre de questions demeurent toutefois sans réponse relativement à la meilleure façon d'utiliser l'amantadine pour maîtriser les épidémies de grippe de type A dans les établissements de soins de longue durée. De plus, deux membres d'une nouvelle classe d'antiviraux appelés inhibiteurs de la neuraminidase ont récemment été brevetés au Canada pour le traitement de la grippe et sont efficaces en prophylaxie. On passe ici en revue les questions relatives à l'utilisation de l'amantadine dans la maîtrise des épidémies de grippe de type A dans les établissements de soins de longue durée pour personnes âgées et les utilisations potentielles des inhibiteurs de la neuraminidase dans ce contexte.

\footnotetext{
${ }^{1}$ Department of Microbiology, Mount Sinai Hospital, University of Toronto, Toronto, Ontario; ${ }^{2}$ Departments of Pharmacology and Therapeutics, Medicine and Medical Microbiology, University of Manitoba, Winnipeg, Manitoba; ${ }^{3}$ Perth District Health Unit, Stratford, Ontario; ${ }^{4}$ York Region Health Services Department, Newmarket, Ontario

Correspondence and reprints: Dr Allison McGeer, Room 1460, Department of Microbiology, Mount Sinai Hospital, 600 University Avenue, Toronto, Ontario M5G 1X5. Telephone 416-586-3118, fax 416-586-3140, e-mail amcgeer@mtsinai.on.ca
} 
$\mathrm{D}$ espite the fact that more than $90 \%$ of residents of long term care facilities in Canada are vaccinated against influenza annually, almost half of such facilities report detecting at least one influenza outbreak each year $(1,2)$. Although there are no randomized, controlled trials assessing the effectiveness of antiviral prophylaxis in the control of outbreaks, amantadine has been shown to be effective in preventing influenza A in exposed persons $(3,4)$, and numerous reports document its success in terminating influenza A spread in the long term care setting (1,2,5-9). Thus, both American and Canadian expert advisory committees recommend antiviral prophylaxis for residents for the control of influenza A outbreaks $(10,11)$, and such prophylaxis has become a standard part of outbreak management in Canadian long term care facilities $(1,2)$. There are, however, numerous areas of disagreement about how best to manage mass prophylaxis, and the advent of neuraminidase inhibitors offers new challenges in selecting the best options for prevention of influenza in this setting. In the present paper, we discuss issues surrounding the initiation and discontinuation of prophylaxis, the use of amantadine and the potential place of neuraminidase inhibitors in outbreak control.

\section{DECISIONS ABOUT THE INITIATION OF PROPHYLAXIS}

Amantadine for antiviral prophylaxis of residents is useful to prevent morbidity and mortality when influenza $\mathrm{A}$ is being transmitted in a long term care facility. For optimal use of prophylaxis, it is important that clusters of acute respiratory infection are detected early, that facilities have the ability to obtain nasopharyngeal swabs and have rapid antigen testing for influenza performed seven days/week, and that consent for the use of prophylaxis be obtained either on admission to the long term care facility or annually before influenza season.

Diagnosing influenza using clinical inquiry and examination is difficult. Overall, the symptom complex with the best predictive value (illness associated with the abrupt onset of fever higher than $38.5^{\circ} \mathrm{C}$ and dry cough) has only a $35 \%$ positive predictive value for the diagnosis of influenza among unvaccinated, elderly adults living independently (12). When influenza is present in the community, a similar constellation of signs and symptoms in healthy younger adults is about $60 \%$ predictive of influenza (13). However, in vaccinated residents of long term care facilities, whose illness may be modified by vaccine, who may not mount a febrile response and who are often unable to describe symptoms clearly, the predictive value of such signs and symptoms is much poorer (14). Therefore, influenza outbreaks in nursing homes can only be reliably diagnosed by laboratory testing in the setting of clusters of acute respiratory illness.

Gomolin et al (15) have suggested that a cluster of infection should be considered to be three residents on one unit who develop acute respiratory illness within $72 \mathrm{~h}$ of each other. In this circumstance, case finding should be enhanced, and nasopharyngeal swabs should be obtained from the initial cases as well as from the next three to five new cases. The identification of two residents with laboratory-confirmed in- fluenza confirms that influenza is being transmitted, and prophylaxis should be started for all asymptomatic residents. With a single laboratory confirmation from the cluster, judgment should be used, and a decision about whether to start prophylaxis should be made jointly by the facility and public health.

Prophylaxis should be offered to residents who are asymptomatic at the time of the decision to initiate mass prophylaxis. Treatment may be considered for those who have had symptoms for less than $48 \mathrm{~h}(16)$. It is important to remember that influenza is a self-limited disease even in elderly nursing home residents, and hospitalization and death are most often due to complications rather than to the influenza itself. Residents who have had symptoms for more than $48 \mathrm{~h}$ will not benefit from antiviral treatment (17). Minimizing the use of antivirals for treatment is particularly important for amantadine, because influenza A strains develop resistance to amantadine very easily when exposed to it (3). Amantadineresistant viruses are as virulent and transmissible as susceptible viruses, and failure of amantadine to control outbreaks due to the emergence of resistance has been identified (17-21). Limiting amantadine treatment to three to five days and discontinuing prophylaxis in residents who develop symptoms may help to obviate the emergence of resistance (22); the use of a neuraminidase inhibitor instead of amantadine for treatment may also be helpful (see below).

In smaller facilities, there is almost always substantial mixing of both residents and staff on different units, so that it is generally essential to offer prophylaxis to all asymptomatic residents in the facility. In larger facilities, it may be possible to limit prophylaxis to one or more geographically separate units. It is important to realize that, when an outbreak is recognized, a substantial number of exposed residents and staff may be in the incubation phase but not yet be ill. The ability to limit prophylaxis to one unit successfully depends on both the degree of contact between staff and residents on the affected unit and other units in the three days before the detection of the outbreak (ie, are residents and staff on other units incubating influenza?), and the extent to which such contact can be prevented over the next few days. Clearly, the vaccination rate among staff is important, because exposed vaccinated staff are less likely to become ill.

Vaccine efficacy in healthy adults younger than 65 years of age is $80 \%$ or greater $(23,24)$, so that current recommendations specify that only unvaccinated staff require chemoprophylaxis $(10,11)$. The majority $(65 \%)$ of facilities across Canada now offer prophylaxis routinely to unvaccinated staff (1). This protects staff and their families from illness, and reduces absenteeism during the outbreak, a time when staffing may be difficult. In addition, because staff are infectious at or before the onset of symptoms (25) and onset may occur in the middle of a shift, prophylaxis likely adds a degree of protection for residents and reduces the risk of propagation of the outbreak. This argument has led a number of long term care facilities and public health units across Canada to require unvaccinated staff to take prophylaxis if they wish to continue to work during outbreaks. The Ontario Labour Relations Board and the Ontario Nurses Association have supported such policies. 
TABLE 1

National Advisory Committee on Immunization recommendations for dosage of amantadine in persons over the age of 65 years

\begin{tabular}{lc}
\hline Creatinine clearance* & Dose \\
\hline $80 \mathrm{~mL} / \mathrm{min}$ or greater & $100 \mathrm{mg} /$ day \\
$60-79 \mathrm{~mL} / \mathrm{min}$ & Alternating $100 \mathrm{mg}$ and $50 \mathrm{mg}$ daily \\
$40-59 \mathrm{~mL} / \mathrm{min}$ & $100 \mathrm{mg}$ every 2 days \\
$30-39 \mathrm{~mL} / \mathrm{min}$ & $100 \mathrm{mg} 2$ times/week \\
$20-29 \mathrm{~mL} / \mathrm{min}$ & $50 \mathrm{mg} 3$ times $/$ week \\
$10-19 \mathrm{~mL} / \mathrm{min}$ & Alternating weekly doses of $100 \mathrm{mg}$ \\
& and $50 \mathrm{mg}$ \\
\hline${ }^{*}$ Calculation of estimated creatinine clearance $(\mathrm{CrCl}):$ \\
For males: $\mathrm{CrCl}(\mathrm{mL} / \mathrm{min})=(140$-age $) \times$ weight $(\mathrm{kg})$ \\
For females: $\mathrm{CrCl}(\mathrm{mL} / \mathrm{min})=0.85 \times \mathrm{CrCl}($ male $)$
\end{tabular}

\section{DECISIONS ABOUT DISCONTINUING PROPHYLAXIS}

In more than $75 \%$ of outbreaks, the initiation of mass antiviral prophylaxis is associated with termination of the outbreak $(1,2,4-9,21)$. Because the efficacy of antivirals in preventing infection is not absolute, particularly in those residents and staff who are incubating the infection when prophylaxis is initiated, a few cases may occur in the first $72 \mathrm{~h}$ after the initiation of prophylaxis. Prophylaxis should be continued until the outbreak is over: that is, until one complete incubation period passes following the infectious period (or period of communicability) in the last case in the facility. In general, the last infectious case occurs in a resident, and significant viral shedding occurs for three to five days after the onset of symptoms $(26,27)$. The incubation period of influenza is one to three days. Thus, prophylaxis should be continued until eight days after the onset of symptoms in the last case.

In about $20 \%$ of outbreaks, new cases may continue to occur more than $72 \mathrm{~h}$ after prophylaxis is started $(1,2,9,21)$, and further investigation is necessary. There are a number of reasons why antiviral prophylaxis may fail to stop the outbreak. First, if amantadine is being used, the virus may be resistant (either at the start of the outbreak or because resistance has developed during the outbreak). Second, another respiratory virus may be co-circulating and causing illness clinically that is indistinguishable from influenza. In one study, at least one case of illness due to another virus was identified in five of six long term care facility outbreaks of influenza (28). Third, new cases may be occurring because nonimmune, unprotected residents or staff continue to propagate the outbreak. Which of these possibilities is occurring can only be determined by diagnostic testing of nasopharyngeal swabs from new cases. Because rapid antigen testing by ELISA is currently available only for influenza and respiratory syncytial virus, testing by direct fluorescent antibody, which can detect influenza, respiratory syncytial virus, parainfluenza and adenovirus, offers advantages in this situation.

Amantadine-resistance testing is not yet available in a sufficiently timely manner for use in outbreak management. Amantadine resistance should be suspected when laboratory- confirmed cases of influenza A continue to occur in residents or staff receiving adequate prophylaxis, particularly if the number of new cases starts to increase again. If resistance is suspected, amantadine should be discontinued and prophylaxis with a neuraminidase inhibitor substituted (see below). If illness is due to a different virus, a clinical decision must be made as to when the last case of influenza occurred. Amantadine may be discontinued eight days after the onset of this case.

\section{DOSING REGIMENS FOR AMANTADINE}

Serum levels of amantadine are affected by variation in both its apparent volume of distribution and the rate of its renal elimination. The apparent volume of distribution of amantadine is most directly related to body weight but is inversely related to dose. Renal elimination is directly related to creatinine clearance. In addition, amantadine renal clearance is one-third less in females than males of the same weight, probably due to a sex difference in renal tubular secretion rate $(29,30)$. The net effect of these interdependent factors in a given patient contributes to the difficulty of designing effective and well tolerated amantadine dosing schedules for frail elderly residents of institutions.

When doses recommended for prophylaxis in younger adults are used in residents of nursing homes, a significant increase in the rate of dose-related side effects of amantadine, including dizziness, irritability, confusion, and the potentiation of adverse events due to drugs with anticholinergic side effects, have been reported $(3,31)$. These side effects may result in falls, fractured hips and deaths in this population (18).

The Canadian National Advisory Committee on Immunization (NACI) (10) has published recommendations on individualized amantadine dosing, taking into account age and estimated creatinine clearance (Table 1$)$. The majority (79\%) of long term care facilities in Canada use these recommendations and report that, if this dosing regimen is used, fewer than $2 \%$ of residents started on amantadine need to have their medication discontinued due to side effects $(1,9)$. Obviously, calculated creatinine clearances are only estimates of true creatinine clearances, and a recent study of amantadine levels in residents (32) found that serum levels may be below those predicted to be effective when this dosing regimen is used. Nonetheless, cumulative experience in Canadian nursing homes suggests that this regimen is safe and effective in controlling influenza A outbreaks $(1,2,9,21)$.

The NACI individualized dosing recommendations have three drawbacks. First, the initial dose of amantadine is $100 \mathrm{mg}$ for most residents, but $50 \mathrm{mg}$ for one group. Because the volume of distribution is independent of creatinine clearance, the loading dose should be based only on weight, not creatinine clearance. Given that the initial dose selected by the NACI guidelines has been found to be associated with a low risk of side effects, it is safe and reasonable to give each resident an initial dose of $100 \mathrm{mg}$. If an influenza outbreak occurs and individualized doses have not been calculated in advance for each resident (as is desirable), this means that an initial dose may be given to each resident before individualized dosing regimens are calculated. Second, the intermittent dosing 
TABLE 2

Proposed once daily dosing schedule for amantadine solution $(10 \mathrm{mg} / \mathrm{mL})$ in persons over the age of 65 years*

\begin{tabular}{lcc}
\hline $\begin{array}{l}\text { Creatinine } \\
\text { clearance }^{+}\end{array}$ & $\begin{array}{c}\text { Initial dose } \\
\text { (day 1) }\end{array}$ & $\begin{array}{c}\text { Subsequent doses } \\
\text { (starting day 2) }\end{array}$ \\
\hline $80 \mathrm{~mL} / \mathrm{min}$ or greater & $100 \mathrm{mg}$ & $100 \mathrm{mg} /$ day $(10 \mathrm{~mL})$ \\
$60-79 \mathrm{~mL} / \mathrm{min}$ & $100 \mathrm{mg}$ & $75 \mathrm{mg} /$ day $(7.5 \mathrm{~mL})$ \\
$40-59 \mathrm{~mL} / \mathrm{min}$ & $100 \mathrm{mg}$ & $50 \mathrm{mg} /$ day $(5 \mathrm{~mL})$ \\
$20-39 \mathrm{~mL} / \mathrm{min}$ & $100 \mathrm{mg}$ & $25 \mathrm{mg} /$ day $(2.5 \mathrm{~mL})$ \\
$10-19 \mathrm{~mL} / \mathrm{min}$ & $100 \mathrm{mg}$ & $-^{\ddagger}$ \\
\hline
\end{tabular}

*Dosing schedule developed based on National Advisory Committee on Immunization guidelines, with daily dosing increments set at $2.5 \mathrm{~mL}$ to permit the use of medicine cups marked at each $2.5 \mathrm{~mL}$. ${ }^{\dagger}$ See Table $1 \mathrm{for}$ method to estimate creatinine clearance. ${ }^{\neq}$No daily dose; if outbreak continues, repeat $100 \mathrm{mg}$ dose every seven days during the outbreak

schedule, with intervals of two to seven days between doses, results in substantial peaks in drug concentrations after subsequent $100 \mathrm{mg}$ doses, which may put residents at increased risk of side effects (33). Finally, some facilities have felt that it is confusing to have dosing schedules for which different residents receive medication in different amounts and on different days.

For these reasons, the authors have developed a second dosing schedule in which all residents receive an initial dose of $100 \mathrm{mg}$ of amantadine, followed by a daily dose of amantadine solution, adjusted for estimated creatinine clearance (Table 2). As with the dosing regimen recommended by NACI, this regimen takes creatinine clearance into account, but does not adjust for other pharmacokinetic effects of the resident's weight and sex (eg, on volume of distribution). It is also simplified to account for the fact that amantadine solution is likely to be dispensed in medication cups marked in $2.5 \mathrm{~mL}$ increments. Pharmacokinetic calculations suggest that this dosing regimen should be as effective as the standard NACI guidelines, without an increase in side effects. It has the disadvantage that, overall, more doses of medication need to be administered. Facilities should take the advantages and disadvantages of the two different schedules into consideration when selecting a regimen for their residents.

For prophylaxis, initial studies in healthy adults under the age of 65 years used the currently recommended dose of $100 \mathrm{mg}$ twice daily. At this dose, annoying neurological side effects (eg, insomnia, dry mouth) are reported by as many as $30 \%$ of subjects. In the largest randomized, controlled trial of amantadine prophylaxis, $20 \%$ of subjects discontinued the drug because of side effects (34). A dose of $100 \mathrm{mg}$ daily has been shown to be effective in prophylaxis in one trial (35). Because this dose is associated with a significantly reduced rate of side effects, it may be preferable for staff prophylaxis.

\section{ROLE OF NEURAMINIDASE INHIBITORS}

By late 1999, two neuraminidase inhibitors with activity against influenza, zanamivar and oseltamivir had been licensed in Canada for the treatment of influenza in adults. There is good evidence from randomized, controlled trials that these medications are also effective in prophylaxis $(36,37)$.
Oseltamivir has been shown to be $80 \%$ effective in preventing influenza in nursing home residents exposed to influenza (38), and zanamivir has been shown to be effective in control of influenza in at least two outbreaks $(39,40)$. Through the influenza season of 1999/2000, numerous public health units and long term care facilities used these medications off label in the management of influenza outbreaks in institutions.

Zanamivir is a powder that is taken via an inhaler. The recommended treatment dose is $10 \mathrm{mg}$ (two puffs) bid; the prophylactic dose is $10 \mathrm{mg}$ (two puffs) daily. About $20 \%$ of long term care facility residents have some difficulty coordinating the inhalations (20). Only about $3 \%$ of a dose is absorbed. In randomized, controlled trials to date, no side effects have been identified, but there continues to be concern about the risk of bronchospasm in patients with asthma. In clinical trials, zanamivir appears well tolerated in patients with mild to moderate asthma (13). However, one patient with severe chronic obstructive lung disease who took repeated doses of zanamivir noted wheezing after each dose and required hospitalization for respiratory distress on the third day of therapy (41). The United States Food and Drug Administration has reported that other patients with asthma or underlying chronic obstructive lung disease have also experienced deterioration after zanamivir inhalation.

Oseltamivir is supplied as a $75 \mathrm{mg}$ capsule, with the adult treatment dose being $75 \mathrm{mg}$ bid and the prophylatic dose being $75 \mathrm{mg}$ daily. A suspension form of this medication is expected to become available within the next two years. Oseltamivir is excreted renally. It is recommended that the treatment dose be halved in persons with creatinine clearances less than $30 \mathrm{~mL} / \mathrm{min}$; no adjustment is required for the prophylactic dose for those with a lesser degree of renal dysfunction. No interactions between oseltamivir and other drugs have been identified. The most common side effects are nausea and vomiting $(13,37,38)$. They are reported to occur most prominently after the first dose, and can be reduced by taking the first dose with food. These symptoms are also more common in females and younger adults (excess rate over placebo $5 \%$ to $9 \%$ ) than in nursing home residents (excess rate over placebo $2.5 \%$ ).

Antiviral resistance can be induced in the laboratory to both neuraminidase inhibitors; however, this resistance is much more difficult to induce than resistance to amantadine (13). In addition, the resistant viruses identified to date have been less infectious than their susceptible counterparts. Resistance to zanamivir has been identified in only one clinical isolate and to oseltamivir in fewer than 10 clinical isolates (13). Because of their activity against influenza A and B, their improved side effect profile, the reduced risk of medication errors when a single dose is used, and the reduced selection of resistance, it seems likely that neuraminidase inhibitors will become the drugs of choice for mass antiviral prophylaxis in long term care facilities. However, more data are required to establish their efficacy, and, at the moment, they are considerably more expensive than amantadine. Institutions, as well as those responsible for the payment of antiviral prophylaxis in nursing home outbreaks, need to look carefully at the overall costs of amantadine (including the cost of annual resident 
assessment and individualized dose calculations), and the potential risks and benefits of each drug before deciding which should be recommended and reimbursed in future seasons. Similarly, facilities and public health departments that are considering offering or requiring staff prophylaxis should take into account not only the drug cost but also the rate of perceived and actual side effects, and its impact on staffing during an outbreak.

There are, however, several situations for which neuraminidase inhibitors are already indicated (Table 3). In the setting of clinical amantadine failures during influenza A outbreaks, continuing influenza A causes serious disease (18-21) and neuraminidase inhibitors are effective in its prevention $(21,38-40,42,43)$. Influenza B outbreaks are associated with substantial morbidity and mortality in long term care facilities (2), and prophylaxis will benefit residents in at least some outbreaks. Data on the impact of prevention of influenza B outbreaks in long term care facilities will be difficult to obtain but are urgently needed.

Amantadine has been associated with an increased risk of seizures in those with seizure disorders (31) and with potentiation of anticholinergic side effects in patients on anticholinergic medications. In such patients, it is difficult to justify the risks of amantadine side effects when other, equally effective medications are available, and the cost of using neuraminidase inhibitors may be offset by the reduced need for added care and investigation when adverse events occur. This is particularly true in settings where a majority of residents have contraindications or relative contraindications. In such settings, using amantadine for some residents and neuraminidase inhibitors for others significantly complicates management in a setting of great stress, and using a neuraminidase inhibitor for all residents may be the preferred strategy.

Finally, the value of amantadine prophylaxis in outbreaks may be compromised by emerging resistance if amantadine is used concomitantly to treat residents with influenza (3). Both amantadine and neuraminidase inhibitors have been shown to reduce the duration and severity of illness in acutely ill adults if treatment can be started within $48 \mathrm{~h}$ of the onset of

\section{REFERENCES}

1. Stevenson C, McArthur M, Abraham E, Naus M, McGeer A. Progress in the control of influenza and pneumococcal disease in Canadian LTCFs - where do we stand? 3rd Decennial Center for Disease Control and Prevention Meeting on Nosocomial Infections. Atlanta, March 5 to 9, 2000. (Abst)

2. Henry B. Summary report of the Ontario influenza 1998/9 season. Public Health Epidemiol Rep Ont 1999;10:144-59.

3. Aoki F. Amantadine and rimantadine. In: Nicholson KG, Webster RG, Hay AJ, eds. Textbook of Influenza. Oxford: Blackwell Science Ltd, 1998:457-76.

4. O'Donoghue JM, Ray CG, Terry DW Jr, Beaty HN. Prevention of nosocomial influenza infection with amantadine. Am J Epidemiol 1973;97:276-85.

5. Arden NH, Patriarca PA, Fasano MB, et al. The roles of vaccination and amantadine prophylaxis in controlling an outbreak of influenza A (H3N2) in a nursing home. Arch Intern Med 1988;148:865-8.

6. Staynor K, Foster G, McArthur M, McGeer A, Petric M, Simor AE. Influenza A outbreak in a nursing home: the value of early diagnosis and the use of amantadine hydrochloride. Can J Infect Control 1994;9:109-11.
TABLE 3

Situations during institutional outbreaks of influenza in which neuraminidase inhibitors may be indicated

\begin{tabular}{|c|c|}
\hline Situation & Rationale \\
\hline $\begin{array}{l}\text { Outbreaks of influenza A in } \\
\text { which cases of confirmed } \\
\text { influenza continue to occur, } \\
\text { with an onset of more than } \\
96 \text { h after the initiation of } \\
\text { amantadine prophylaxis }\end{array}$ & $\begin{array}{l}\text { These cases may be due to the } \\
\text { emergence of amantadine } \\
\text { resistance. In this setting, } \\
\text { amantadine is no longer effective }\end{array}$ \\
\hline Outbreaks of influenza B & $\begin{array}{l}\text { Amantadine is not effective against } \\
\text { influenza B; neuraminidase } \\
\text { inhibitors are }\end{array}$ \\
\hline $\begin{array}{l}\text { Residents who are at risk of } \\
\text { serious side effects from } \\
\text { amantadine* }\end{array}$ & $\begin{array}{l}\text { Includes those who: } \\
\text { - require multiple major tranquilizers } \\
\text { or other medications with } \\
\text { anticholinergic side effects } \\
\text { - have seizure disorders }\end{array}$ \\
\hline $\begin{array}{l}\text { Treatment of symptomatic } \\
\text { residents in outbreaks of } \\
\text { influenza } A \text { in which } \\
\text { amantadine is being used for } \\
\text { prophylaxis }\end{array}$ & $\begin{array}{l}\text { Amantadine resistance is more likely } \\
\text { to arise in this setting due to the } \\
\text { exposure of the virus to amantadine } \\
\text { in treated patients. Resistance arises } \\
\text { much less commonly to } \\
\text { neuraminidase inhibitors. In } \\
\text { addition, data supporting the use of } \\
\text { neuraminidase inhibitors for } \\
\text { treatment are better than those } \\
\text { for amantadine }\end{array}$ \\
\hline
\end{tabular}

*Where patients with relative contraindications to amantadine make up a majority of residents (eg, geriatric psychiatric units), using a neuraminidase inhibitor for all residents may simplify outbreak management

symptoms $(3,12)$. Although data on the benefits of treatment in the frail elderly are few, there is no reason to believe that treatment efficacy will be different in this age group, and treatment of acute influenza in the frail institutionalized elderly may be reasonable, as long as it is started within the first $48 \mathrm{~h}$ of symptoms. Treatment with amantadine will increase the risk of selection for amantadine resistance and failure to control the outbreak. Thus, in an outbreak in which amantadine is being used for mass prophylaxis of residents, neuraminidase inhibitors should be considered for the treatment of illness.

7. Kobayashi JM. Control of influenza A outbreaks in nursing homes: amantadine as an adjunct to vaccine - Washington, 1989-90. MMWR Morb Mortal Wkly Rep 1991;40:841-4.

8. Libow LS, Neufeld RR, Oslon E, Breuer B, Starer P. Sequential outbreak of influenza A and B in a nursing home: efficacy of vaccine and amantadine. J Am Geriatr Soc 1996;44:1153-7.

9. Tamblyn SE. Influenza control in long term care facilities: the Perth County experience. Options for the Control of Influenza III, Cairns, May 4 to 9, 1996. (Abst R4-7)

10. An Advisory Committee Statement (ACS). National Advisory Committee on Immunization (NACI). Statement on influenza vaccination for the 1998-1999 season. Can Commun Dis Rep 1998;24:1-12.

11. Advisory Committee on Immunization Practice. Prevention and control of influenza: recommendations of the advisory committee on immunization practices. MMWR Morb Mortal Wkly Rep 2000;48(RR03):1-38.

12. Goevart TM, Dinant GJ, Aretz K, Knottnerus JA. The predictive value of influenza symptomatology in elderly people. Fam Pract 1998;15:16-22.

13. Gubareva LV, Kaiser L, Hayden FG. Influenza virus neuraminidase inhibitors. Lancet 2000;355:827-35. 
14. Simor AE, Augustin A, Staynor K, et al. Influenza A in elderly nursing homes residents: evaluation of vaccine efficacy and case definitions of influenza-like illness. 33rd Interscience Conference on Antimicrobial Agents and Chemotherapy. New Orleans, October 17 to 20, 1993. (Abst 1383)

15. Gomolin IH, Leib HB, Arden NH, Sherman FT. Control of influenza outbreaks in the nursing home: guidelines for diagnosis and management. J Am Geriatr Soc 1995;43:71-4

16. Monto AS. Guidelines for the clinical use of antivirals. In: Nicholson KG, Webster RG, Hay AJ, eds. Textbook of Influenza. Oxford: Blackwell Science Ltd, 1998:506-14.

17. Mast EE, Harmon MW, Gravenstein S, et al. Emergence and possible transmission of amantadine-resistant viruses during nursing home outbreaks of influenza A (H3N2). Am J Epidemiol 1991;134:988-97.

18. Degelau J, Somani S, Cooper S, Guay D, Crossley K. Amantadine-resistant influenza A in a nursing facility. Arch Intern Med 1992;152:390-2.

19. Houck P, Hemphill M, LaCroix S, Hirsh D, Cox N. Amantadine-resistant influenza A in a nursing homes. Identification of a resistant vurus pror to drug use. Arch Intern Med 1995;155:533-7.

20. Lee C, Loeb M, Phillips A, et al. Use of zanamivir to control an outbreak of influenza A. 39th Interscience Conference on Antimicrobial Agents and Chemotherapy. San Francisco, September 26 to 29, 1999. (Abst 283)

21. Tamblyn SE. Antiviral use during influenza outbreaks in long term care facilities. Options for the Control of Influenza IV. Crete, September 23 to 28, 2000. (Abst 255)

22. Hall CB, Dolin R, Gala CL, et al. Children with influenza A infection: treatment with amantadine. Pediatrics 1987;80:275-82.

23. Nichol KL, Lind A, Margolis KL, et al. The effectiveness of vaccination against influenza in healthy, working adults. N Engl J Med 1995;333:889-93.

24. Wilde JA, McMillan JA, Serwint J, Butta J, O'Riordan MA, Steinhoff MC. Effectiveness of influenza vaccine in health care professionals: a randomized trial. JAMA 1999;281:908-13.

25. Dolin R. Influenza: current concepts. Am Fam Physician 1976;14:72-7.

26. Benenson AS, ed. Control of Communicable Diseases in Man, 16th edn. Washington: American Public Health Association, 1995:245-51.

27. Kilbourne ED. Influenza in man. In: Influenza. New York: Plenum Publishing Corporation, 1987:157-218.

28. Loeb M, McGeer A, McArthur M, Peeling RW, Petric M, Simor AE. Prospective surveillance for outbreaks of respiratory infection in long-term care facilities. CMAJ 2000;162:1133-7.

29. Gaudry SE, Sitar DS, Smyth DD, McKenzie JK, Aoki FY. Gender and age as factors in the inhibition of renal clearance of amantadine by quinine and quinidine. Clin Pharmacol Ther 1993;54:23-7.

30. Wong LT, Sitar DS, Aoki FY. Chronic tobacco smoking and gender as variables affecting amantadine disposition in healthy subjects. Br J Clin Pharmacol 1995;39:81-4.

31. Atkinson WL, Arden NH, Patriarca PA, Leslie N, Lui KJ,
Gohd R. Amantadine prophylaxis during an institutional outbreak of type A (H1N1) influenza. Arch Intern Med 1986;146:1751-6.

32. Sitar DS, Kolbe F, Papaioannou A, Campbell G. Individualized dosing and side effects of amantadine during influenza A outbreaks in nursing homes. 2000 Annual Meeting of the American Society for Clinical Pharmacology and Therapeutics. Clin Pharmacol Thera 2000;67:153. (Abst PIII-50)

33. Hayden FG, Hoffman HE, Spyker DA. Differences in side effects of amantadine hydrochloride and rimantadine hydrochloride related to differences in pharmacokinetics. Antimicrob Agents Chemother 1983;23:458-464

34. Dolin R, Reichman RC, Madore HP, Maynard R, Linton PN, Webber-Jones J. A controlled trial of amantadine and rimantadine in the prophylaxis of influenza A infection. N Engl J Med 1982;307:580-4.

35. Reuman PD, Bernstein JI, Keefer MC, Young EC, Sherwood JR, Schiff GM. Efficacy and safety of low dosage amantadine hydrochloride as prophylaxis for influenza A. Antiviral Res 1989;11:27-40.

36. Monto AS, Robinson DP, Herlocher L, Hinson JM, Elliott M, Crisp A. Zanamivir in the prevention of influenza among healthy adults. JAMA 1999;282:31-6.

37. Hayden FG, Atmar RL, Schilling M, et al. Use of the selective oral neuraminidase inhibitor oseltamivir to prevent influenza. N Engl J Med 1999;341:1336-43.

38. Peters PH, Norwood P, DeBock V, et al. Oseltamivir is effective in the long term prophylaxis of influenza in vaccinated frail elderly. II International Symposium on Influenza and other Respiratory Viruses. Grand Cayman, December 10 to 12, 1999.

39. Hirji Z, O'Grady S, Bonham J, et al. Utility of zanamivir for the treatment and prophylaxis of concomitant influenza A and B infection in a complex continuing care and medical rehabilitation population. 39th Interscience Conference on Antimicrobial Agents and Chemotherapy. San Francisco, September 26 to 29, 1999. (Abst 1701)

40. Lee W, Loeb M, Phillips A, et al. Use of zanamivir to control an outbreak of influenza A. CHICA-Canada Annual Meeting. Toronto, May 29 to 31, 2000. (Abst)

41. Williamson JC, Pegram PS. Respiratory distress associated with zanamivir. N Engl J Med 2000;342:661-2.

42. Neuraminidase inhibitors for treatment of influenza A and B infections. MMWR Morb Mortal Wkly Rep 1999;48(RR-14):1-9.

43. Bowles SK, Vearncombe M, McGeer A, et al. Use of oseltamivir in outbreaks of influenza in Ontario long term care facilities. Canadian Association of Clinical Microbiology and Infectious Diseases, Ottawa, Ontario, November 5 to 8, 2000. 


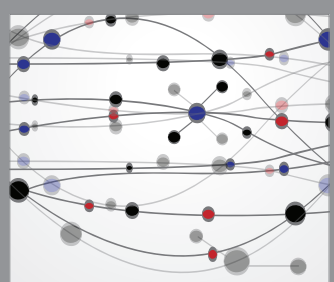

The Scientific World Journal
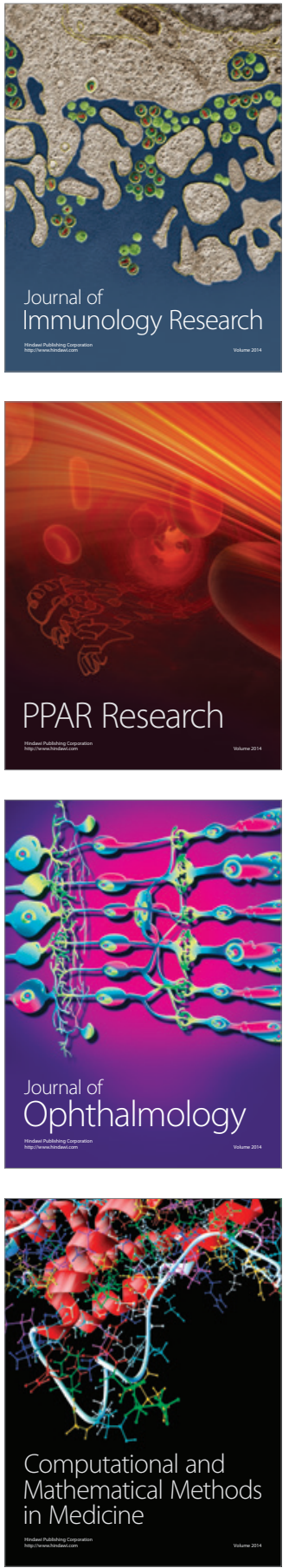

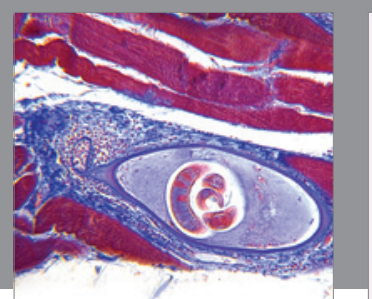

Gastroenterology Research and Practice

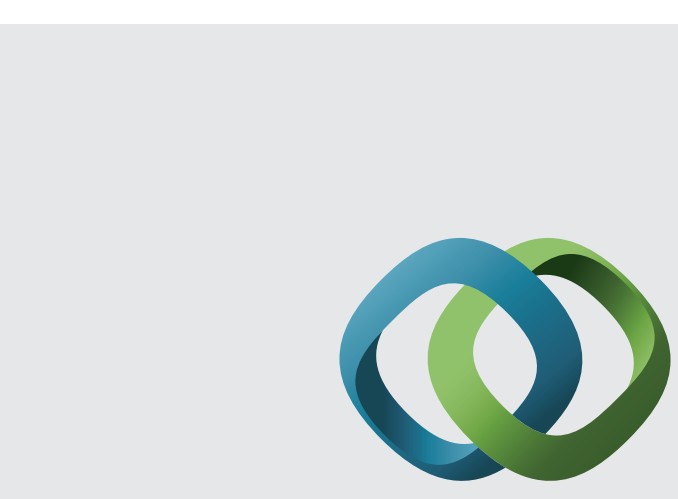

\section{Hindawi}

Submit your manuscripts at

http://www.hindawi.com
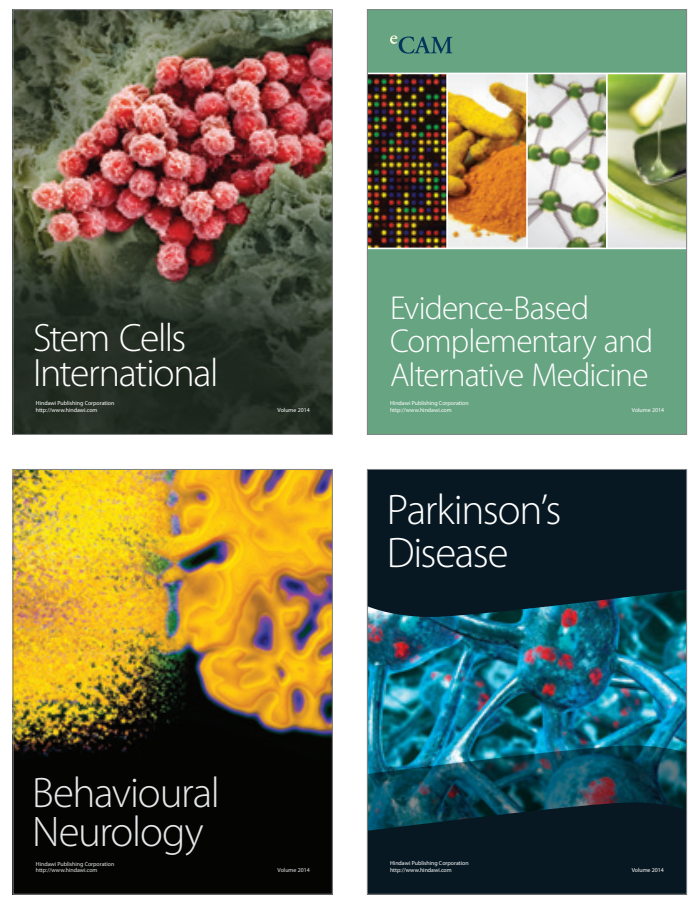
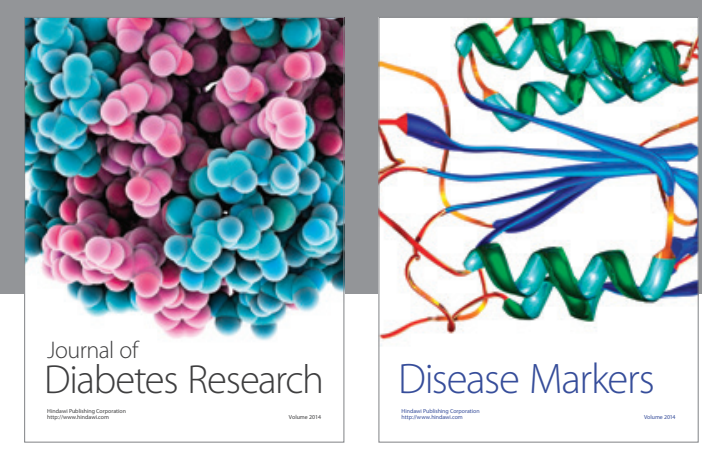

Disease Markers
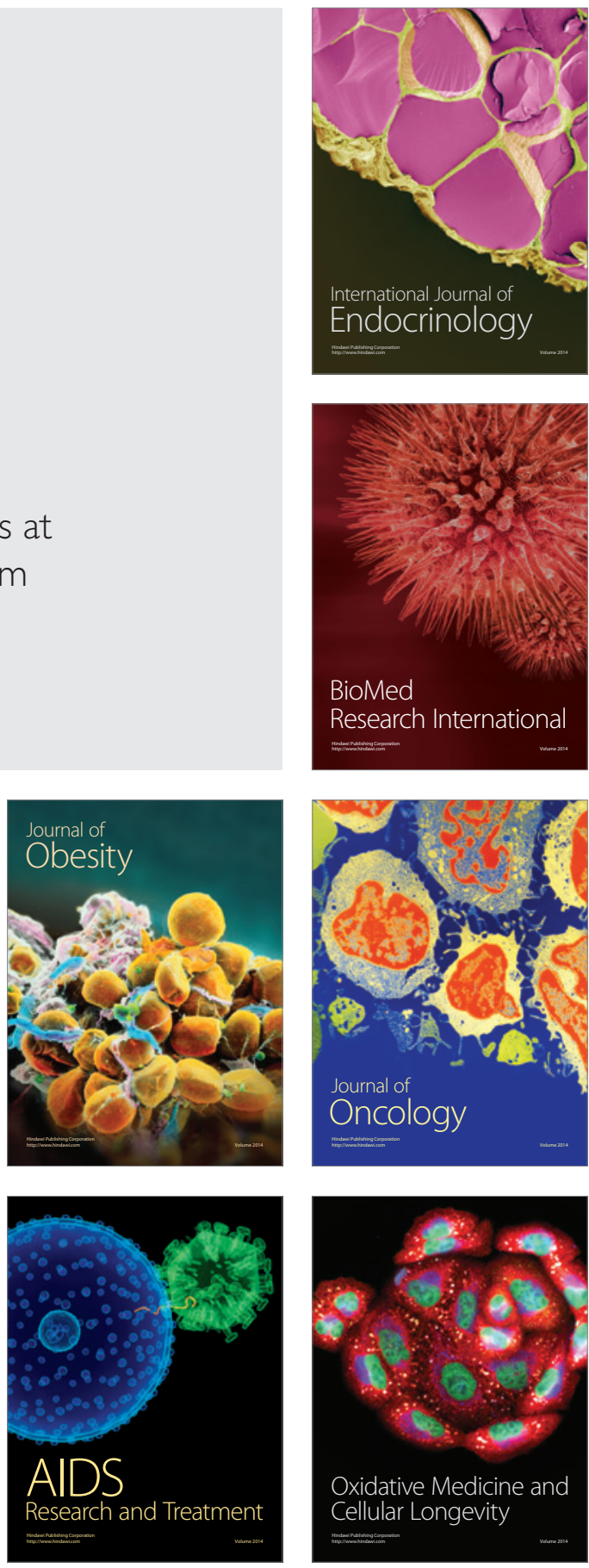